\title{
Correction to: Medical Students' Efforts to Integrate and/or Reclaim Authentic Identity: Insights from a Mask-Making Exercise
}

\author{
Johanna Shapiro ${ }^{1} \cdot$ Julie Youm $^{2} \cdot$ Michelle Heare $^{3}$ - Anju Hurria ${ }^{4} \cdot$ Gabriella Miotto $^{5}$. \\ Bao-Nhan Nguyen ${ }^{2} \cdot$ Tan Nguyen $^{1} \cdot$ Kevin Simonson $^{6} \cdot$ Atur Turakhia $^{4}$ \\ Published online: 19 December 2018 \\ C Springer Science+Business Media, LLC, part of Springer Nature 2018
}

\section{Correction to: Journal of Medical Humanities (2018) 39:483-501 https://doi.org/10.1007/s10912-018-9534-0}

The authors would like to correct a misspelling in the name of one of the authors due to a typographical error. The name should read Atur Turakhia, not Artur Turakhia. This does not change the conclusions or interpretations presented.

Publisher's Note Springer Nature remains neutral with regard to jurisdictional claims in published maps and institutional affiliations.

The online version of the original article can be found at https://doi.org/10.1007/s10912-018-9534-0

Johanna Shapiro

jfshapir@uci.edu

1 Department of Family Medicine, University of California Irvine, School of Medicine, Rte 81, Bldg 200, Ste, 835, Orange, CA 92868, USA

2 Department of Emergency Medicine, University of California, Irvine School of Medicine, 836 Health, Sciences Road, Irvine, CA 92697, USA

3 Department of Psychiatry and Behavioral Sciences, University of California, Davis School of Medicine, 2230 Stockton Blvd., Sacramento, CA 95817, USA

4 Department of Psychiatry and Human Behavior, UC Irvine Medical Center, 101 City Dr. South, Bldg 3, Orange, CA 92868, USA

5 The Children's Clinic, 455 E Columbia St, Suite 201, Long Beach, CA 90806, USA

6 University of California Riverside, School of Medicine, 900 University Ave., Riverside, CA 92521, USA 